\title{
Análisis espacial de la expansión urbana y la incidencia de las políticas habitacionales en la ciudad de General José de San Martín (Provincia del Chaco, Argentina)
}

\author{
Spatial analysis of urban expansion and the incidence of housing policies \\ in the city of General José de San Martín (Province of Chaco, Argentina)
}

\author{
Julio César Meza ${ }^{1^{*}}$ (1) \\ Mirta Liliana Ramírez ${ }^{2}$ (iD
}

\section{Resumen}

El objetivo de este trabajo es analizar la expansión urbana de la ciudad de General José de San Martín, Provincia del Chaco (Argentina), e identificar la incidencia de los planes habitacionales estatales como uno de los principales elementos de la conformación de áreas de crecimiento horizontal en las ciudades. La investigación centrada especialmente en aspectos tales como la distribución y la cuantificación de las superficies de las nuevas áreas de expansión y de suelo ocupadas por los conjuntos habitacionales tomando el periodo entre los años 1911 y 2017, se basó en la aplicación de Teledetección y el empleo de Sistemas de Información Geográfica (SIG), tanto para el análisis espacial como para la representación cartográfica. Las principales fuentes de información han sido las imágenes satelitales de las misiones Landsat 5 y 8 , y capas en formato vectorial. Como principal resultado se destaca la expansión de la mancha urbana en el periodo analizado y la incidencia de la ejecución de conjuntos habitacionales del Estado como una de las causas de dicho proceso. De esta manera se pudo generar evidencias respecto al grado de intervención estatal en la configuración del modelo territorial actual de la ciudad.

Palabras clave: Crecimiento urbano; Suelo urbano; Políticas habitacionales; Teledetección; Provincia del Chaco.

\begin{abstract}
This work analyses the urban expansion of the city of General José de San Martín in the province of Chaco (Argentina) and identifies state housing plans as one of the main elements in the appearance of growth areas in the city. The research focuses on aspects such as the distribution and quantification of the surface of the new areas of expansion and land occupied by the housing complexes between 1911 and 2017. It is based on the application of remote sensing and geographic information systems for spatial analysis and cartographic representation. The main sources of information have been the satellite images from the Landsat 5 and 8 missions and vector format layers. The main result is to reveal the expansion

1 Instituto de Investigación para el Desarrollo Territorial y del Hábitat Humano (IIDTHH) - (Consejo Nacional del Investigaciones Científicas y Técnicas CONICET - Universidad Nacional del Nordeste UNNE). Departamento de Geografía, Facultad de Humanidades, Universidad Nacional del Nordeste. Argentina. julio_4152@hotmail.com *Autor para correspondencia

2 Instituto de Investigación para el Desarrollo Territorial y del Hábitat Humano (IIDTHH) - (Consejo Nacional del Investigaciones Científicas y Técnicas CONICET - Universidad Nacional del Nordeste UNNE). Departamento e Instituto de Geografía, Facultad de Humanidades, Universidad Nacional del Nordeste. Argentina. liliana.ramirez.resistencia@gmail.com
\end{abstract}


of the urban area in the period analysed and the incidence of the execution of state housing complexes as one of the causes of this process. In this way it is possible to generate evidence regarding the degree of state intervention in the configuration of the current territorial model of the city.

Keywords: Urban growth; urban soil; housing policies; remote sensing; Province of Chaco.

\section{Introducción}

La ciudad de General José de San Martín (Chaco, Argentina) es un asentamiento considerado de tamaño intermedio en el sistema urbano provincial y cumple un rol importante como nodo regional en el noreste de la provincia. Al igual que los demás poblados de dicho sistema, otras ciudades de la región nordeste del país y de todo el territorio nacional, en las últimas décadas vio modificada su configuración inicial estimulada por la dinámica poblacional y productiva de la región, y de la provincia en general.

Este trabajo tiene como objetivo analizar la expansión urbana de la ciudad de General José de San Martín (Provincia del Chaco), desde 1911 hasta el año 2017, e identificar la incidencia espacial de la ejecución de los planes habitaciones del Estado en la conformación de nuevas áreas de crecimiento expansivo. La investigación se centró especialmente en aspectos tales como la distribución y la cuantificación de las superficies las áreas de expansión por periodos y de suelo ocupadas por los conjuntos habitaciones mediante el uso de Sistemas de Información Geográfica. En ese sentido, se han planteado algunos interrogantes tales como ¿cuál es la extensión de área urbana que aumentó en cada década del periodo de estudio? ¿Cuál es la relación con el crecimiento poblacional? y ¿cuál es la superficie ocupada por los planes de viviendas estatales, es decir, cuál fue la incidencia territorial de estas políticas en dicho procesos de expansión?. De esta manera, y a través de futuros trabajos, se pretende demostrar cuales son los diferentes elementos y las formas de producción de suelo urbano que están determinando el desarrollo urbano actual y generar un aporte al conocimiento de las diversas modalidades de ocupación de suelo urbano en las ciudades de tamaño intermedio en el sistema urbano provincial.

\subsection{Aspectos teóricos-conceptuales}

En palabras de Azócar, Sanhuesa y Henríquez (2003) "La ciudad es el hábitat humano por excelencia; la proporción de población urbana en comparación con la población rural y el crecimiento acelerado de las ciudades, tanto en habitantes como en extensión, son fenómenos globales que así lo demuestran" (p. 3). La concentración de los grupos sociales en áreas urbanas y la consecuente expansión de éstas son fenómenos ya conocidos, que requieren cada vez más de una atenta mirada de académicos y decisores políticos, así como de espacios de trabajo conjunto entre ambos, pues así lo avalan el amplio abanico de estudios vinculados con estos temas y que muchas veces ponen en evidencia la desarticulación entre estos actores.

La ciudad es el espacio por excelencia en el que la sociedad se reproduce, donde los asentamientos humanos se expresan físicamente y en su proceso de crecimiento pueden reconocerse varias etapas: la expansión, la ciudad crece transformando el suelo rural en urbano vinculado al tipo de actividades que se realizan y donde ocurre la subdivisión de parcelas y apertura de nuevas calles, la consolidación, está vinculado al tendido de las redes de servicios públicos y construcción de infraestructura y la tercera etapa es la densificación, sucede cuando las áreas consolidadas comienzan a crecer en altura o simplemente el aumento de población por unidades de superficies. Estas etapas conviven de manera simultánea en la ciudad: mientras que en un extremo crece, en otro se consolida y en otros (generalmente el centro) se densifica (Tella, s/f; Ramírez y Pértile, 2013).

Dentro de las etapas o fases mencionadas, este trabajo hará hincapié en la primera de ellas, la expansión, entendida como proceso vinculado al aumento por extensión de la mancha urbana mediante modalidades históricamente determinadas por el contexto social, económico y político en que se materializan, las cuales se expresan territorialmente en la estructura urbana y del entorno (Lancioni, Dellachaux y Ríos, 2012), aunque indirectamente se enfatizará en la consolidación ya que es una etapa implícita en la construcción de conjuntos habitacionales debido al tendido de redes de servicios que acompaña dicho proceso.

Tal como lo mencionan Azócar et al. (2003) existen factores globales que explican la evolución reciente de las ciudades en un contexto de globalización económica, pero también es posible identificar 
factores regionales y locales que le otorgan rasgos propios al desarrollo urbano de los diferentes centros. Atendiendo a factores locales, puede mencionarse uno en particular y es la situación socioeconómica de la población lo que se traduce en procesos demográficos y de acceso diferencial al suelo urbano. "En muchas ciudades de América Latina, el surgimiento de nuevas zonas residenciales, comercios, equipamientos y servicios destinados a grupos sociales cada vez más segregados espacialmente ha sido un importante factor de crecimiento urbano" (Azócar et. al, 2003, p.80).

El incremento poblacional también como parte del proceso de crecimiento urbano, repercute en la expansión incesante del perímetro de las ciudades, la cual no es perceptible a simple vista sino que con los años se hace evidente la anexión de pequeños terrenos en las periferias, que se van densificando gradualmente. Es así que se consolidan zonas que inicialmente no han sido consideradas para habitar, se subdividen o se lotean y se ocupan. La subdivisión del territorio se hace posible porque diferentes actores locales o provinciales lotean los predios, de allí que las ciudades no se expanden con la misma tasa de ocupación en todos los sentidos, así como tampoco con las mismas modalidades de subdivisión, esto depende de los diversos factores que influyen en la demanda (Bazant, 2008).

Tanto las causas del crecimiento urbano como sus consecuencias son aspectos que se advierten con mayor frecuencia en las áreas metropolitanas o en los grandes centros que estructuran los sistemas urbanos nacionales y regionales; sin embargo, estos procesos también son propicios de ser indagados y estudiados en ciudades de menor tamaño que adquieren cada vez más importancia como nodos regionales e interprovinciales, y ante esto es pertinente preguntarnos ¿Cómo crecen las ciudades intermedias de los territorios o jurisdicciones provinciales?. Dentro de las transformaciones que se advierten en dichos sistemas podemos mencionar uno en particular y es el hecho de que las ciudades intermedias - entendidas como los asentamientos que funcionan como centros de intermediación económica, de interacción social y cultural entre espacios locales/territoriales y los regionales/nacionales (Manzano y Velázquez, 2015) - que conforman sistemas urbanos de estados provinciales comienzan a ser las protagonistas de estos cambios y, en consecuencia, ven la necesidad de desplegar sus propias estrategias de desarrollo y anticiparse a externalidades no deseadas. Ello se advierte, por ejemplo, en el incremento que la población ha experimentado en los últimos 25 años en las ciudades intermedias latinoamericanas que adquirieron un rol decisivo en el escenario internacional.

En este contexto, las ciudades de la Provincia del Chaco (República Argentina) iniciaron hace varias décadas procesos de crecimiento poblacional y expansión urbana con diferentes características pero con similares consecuencias. Es así entonces que estos procesos de urbanización se reconocen a nivel global y aún cuando las causas de índole económica y social son muy diversas, las consecuencias son comunes y evidentes, de allí que, como señalan Dillón, Cossio y Pombo (2010) "Identificar los procesos de crecimiento y expansión y sus efectos sobre el valor que el suelo urbano adquiere, es una herramienta fundamental para intervenir en los problemas urbanos antes de su ocurrencia" (p. 1).

\subsection{Las políticas habitaciones y los planes de viviendas}

\section{Como expresan Buzai y Baxendale (2013):}

El proceso de organización del territorio es el resultado de múltiples interacciones entre la sociedad y el medio, a través de la evolución histórica, esta organización puede haberse generado de forma espontánea o de acciones voluntarias, cuando están impulsadas por organismos de planificación (p. 23).

Siguiendo esta idea, debemos entender a la ciudad y su entorno como un territorio que se organiza a partir de la combinación de diversos elementos y acciones. En este proceso de organización de la ciudad, el espacio urbano tiende a demandar en mayor medida la intervención del Estado, que lo convierte en casi el único medio por el que los sectores populares pueden acceder a una vivienda con equipamientos e infraestructuras mínimas.

En ese sentido, las políticas públicas en materia habitacional es un conjunto de decisiones que se dan en el entramado político que resulta de las mediaciones y la correlación de fuerzas e intereses, en las cuales el Estado interviene directa o indirectamente en la cuestión y forman parte de la política habitacional las regulaciones $\mathrm{u}$ acciones en aspectos tales como los usos suelo, los sectores productivos, el sector externo (aranceles de importación de materiales, importación de tecnologías); las formas de financiamiento de la vivienda, las políticas de precios de alquileres y las inversiones directas o la provisión de servicios habitaciones por parte del Estado (construcción de viviendas, infraestructura, etc.) (Del Río, 2012). 
El Estado a través de este conjunto de acciones se posiciona como un importante actor de la expansión de las ciudades, quien a través de diferentes intervenciones incrementa las superficies de uso destinadas a actividades urbanas en las periferias de las ciudades. En relación a su rol como actor interviniente, sus implicancias territoriales se plasman "por un lado como un fuerte consumidor de tierra urbana interesado en la adquisición de grandes superficies destinadas a la construcción de viviendas sociales y, por otro, ejecutando proyectos e intervenciones en la infraestructura y equipamientos públicos" (Dillón et al., 2010, p. 14). De allí que muchas de las transformaciones que se dan en el territorio, por ejemplo a través de las políticas habitacionales, concuerdan con los patrones de expansión visibles en las manchas urbanas.

De esta manera, desde hace décadas en Argentina, el Estado es un actor protagónico en la producción de suelo urbano mediante diversos mecanismos y uno de ellos es el emplazamiento de conjuntos habitacionales a través de la gestión de los organismos de promoción de la vivienda social como son los Institutos de Viviendas. Por vivienda social se entiende a "aquella residencia que es producto de las políticas habitacionales dirigidas a los grupos más desposeídos de la sociedad, que no pueden optar por sus propios recursos a las viviendas del mercado inmobiliario" (Sardi, 2015, p. 36).

Al respecto Dillón y Cossio (s/f_b) señalan:

La construcción masiva de viviendas sociales es la respuesta que el Estado ha brindado para atenuar el déficit habitacional producido por el aumento de la urbanización y el deterioro progresivo de las condiciones económico-sociales, que impide a sectores cada vez más numerosos, acceder por sus propios medios a una vivienda digna y a servicios elementales básicos (pág. 1). Estas viviendas generalmente agrupadas en grandes conjuntos habitacionales, se convierte en elementos destacados de la estructura urbana, especialmente en las periferias de las grandes ciudades y en los asentamientos intermedios y pequeños (p. 2).

En cuanto a su relación con los procesos de expansión de las ciudades se debe tener en cuenta que las políticas de tierra y vivienda junto con los desarrollos inmobiliarios, poseen una fuerte incidencia en la conformación de las áreas de expansión urbana, contribuyendo a la dispersión y fragmentación socio-espacial ya que estas intervenciones, muchas veces pueden impulsar el crecimiento hacia áreas no previstas, y presionar sobre otros usos de la tierra, como los espacios verdes abiertos y los agropecuarios, e incluso han resultado incompatibles con la preservación de los recursos ambientales (Lancioni et al., 2012). El crecimiento expansivo de las ciudades en general no suele ser un proceso planificado, o bien el grado de planificación es pequeño y en este contexto, las políticas de viviendas constituyen uno de los pocos elementos de intervención planificada por el Estado (Gómez López, 2002). Sin embargo, dichas intervenciones no suelen estar insertas en un marco de planificación urbana mayor, debido, muchas veces, a la ausencia misma de ésta.

Ante este panorama visible y poco alentador en las grandes ciudades, las de menor tamaño advierten la necesidad de una planificación urbana que, entre otros aspectos de implicancia territorial, considere y tenga en cuenta la localización de futuros conjuntos de viviendas sociales y demás modalidades de ocupación del territorio urbano y periurbano. En ese sentido, las tecnologías de manejo de información geográfica deben ser tenidas en cuenta, entre otros aspectos, para la producción y actualización de la información sobre la configuración de las ciudades, y también como insumo necesario para las posteriores fases de planificación y gestión territorial.

Entre los años 1970 y 2010, las ciudades intermedias del Chaco han sido protagonistas de los cambios del sistema urbano provincial, en principio, por el notable crecimiento poblacional en términos relativos de estos centros urbanos en relación al Área Metropolitana del Gran Resistencia (AMGR), acompañado de la constante ampliación de sus manchas urbanas que generó cambios en las coberturas y usos del suelo de sus áreas periurbanas mostrando tendencias a ciudades dispersas de baja densidad (Ramírez y Pértile, 2013, 2017 y Ramírez, 2018). En este contexto, dichos estudios realizados en las ciudades chaqueñas, así como contribuciones similares de diversas ciudades, han demostrado que las técnicas de Teledetección y el uso de Sistemas de Información Geográfica (SIG) son indispensables para el análisis de los cambios ocurridos en el espacio urbano como aportes indiscutibles a la planificación territorial. El estudio de la dinámica espacial a través de la dimensión temporal constituye una tarea de gran importancia en la investigación científica que, con la ayuda de los Sistemas de Información Geográfica ha visto ampliada las posibilidades de modelización y análisis del espacio geográfico y, en particular, aspectos orientados al estudio del crecimiento urbano y cambios en los usos del suelo, generando valiosos aportes metodológicos a los estudios urbanos y regionales (Humacata y Buzai, 2018). 


\section{Metodología}

\section{1. Área de estudio}

La ciudad de General José de San Martín, cabecera del departamento Libertador General San Martín, se localiza en el noreste de la provincia del Chaco, Argentina y sus coordenadas geográficas son $26^{\circ} 32^{\prime}$ 00" Sy 59 20'30" O (Figura 1). Según el Censo Nacional de Población, Hogares y Viviendas 2010 cuenta con una población de 28.383 habitantes. La base productiva siempre estuvo ligada a la producción agrícola y ganadera, además de realizarse otro tipo de actividades de importancia regional como la apicultura, el comercio y la actividad industrial con la presencia de numerosas ladrillerías.

Figura 1. Localización del área de estudio

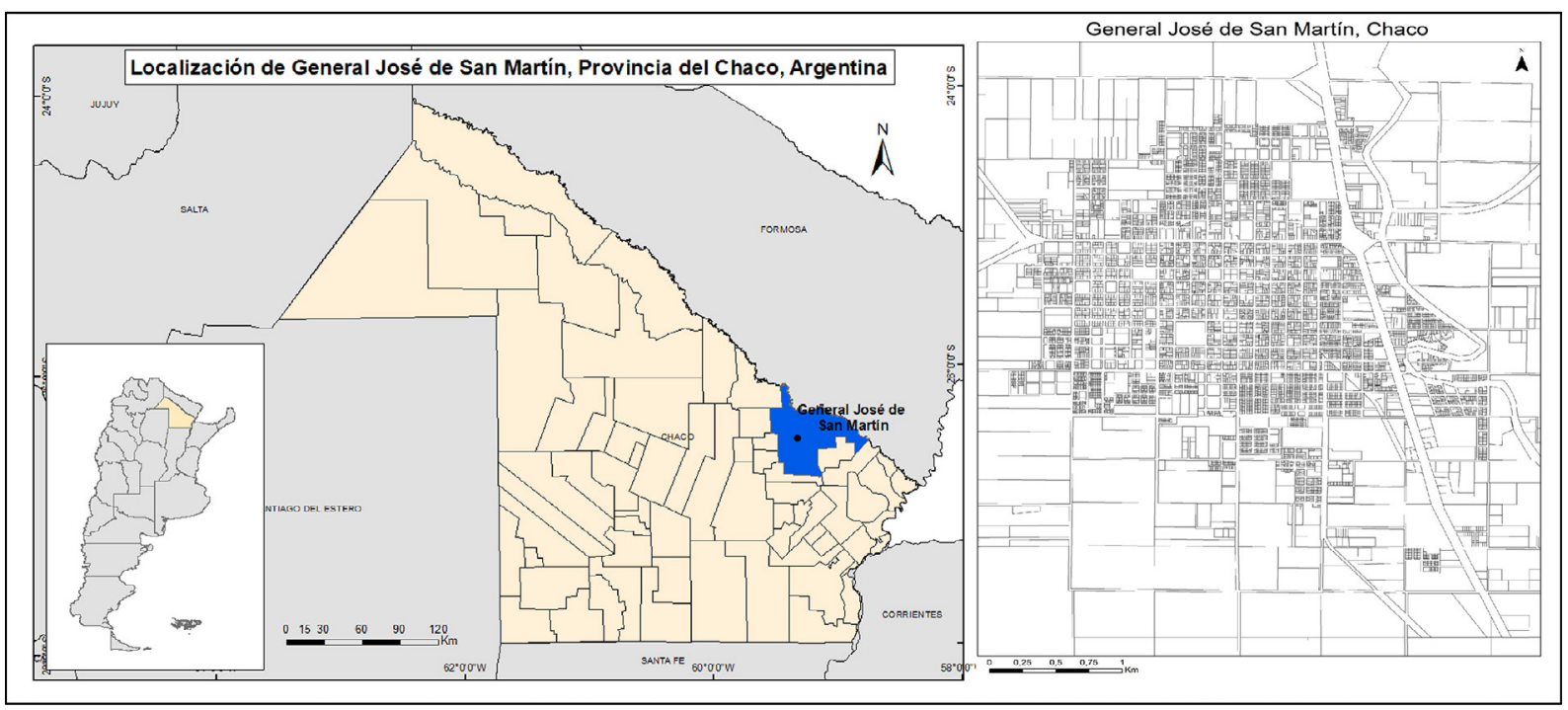

Fuente: Instituto Geográfico Nacional (IGN) y el Instituto Provincial de Desarrollo Urbano y Vivienda de la Provincia del Chaco (IPDUV). Elaboración propia

\subsection{Método y fuentes de trabajo}

El desarrollo de este trabajo incluye tres etapas metodológicas (Figura 2).En primer lugar, para analizar la evolución de la mancha urbana se utilizaron un plano histórico del año 1911 e imágenes satelitales de las plataformas Landsat 5 (sensor TM - ThematicMapper) y Landsat 8 (sensores OLI - OperationalLandImagery TIRS-Thermalinfrared Sensor) suministradas por el Servicio Geológico de los Estados Unidos o USGS por sus siglas en inglés, las mismas corresponde a los años 1984, 1991, 2001, 2010 y 2017. Una vez obtenidas las imágenes satelitales se siguieron los siguientes pasos, mediante el uso de herramientas de Sistemas de Información Geográfica (SIG): se procedió al recorte del área de estudio y a la composición de las bandas multiespectrales 432 para la imagen de Landsat 5 y 543 para Landsat 8, esta combinación permite resaltar y diferenciar las coberturas de la tierra como ser urbano, cultivos, cuerpos y cursos de agua o vegetación nativa.

En un segundo momento, a partir de la digitalización se elaboraron las capas vectoriales de la mancha urbana de los seis momentos antes mencionados y se extrajo el valor de superficie del área urbanizada en cada período y luego se realizó el borrado del área urbanizada en un periodo anterior, obteniendo de esta manera el área urbanizada (AU) en cada periodo. Con el fin de relacionar la expansión urbana con el crecimiento poblacional se analizaron los datos de los Censos Nacionales de Población de los años 1980, 1991, 2001 y 2010 del Instituto Nacional de Estadísticas y Censos (INDEC). Los geoprocesamientos realizados en la segunda parte fueron empleados para determinación del área urbanizada en cada período correspondiente a los cortes temporales utilizados (1911-1984,1984-1991, 1991-2001, 2001-2010 y 2010-2017) mediante la herramienta de borrado o Erase, y luego la intersección de éstas con la de planes de viviendas con la herramienta Intersect, todas estas herramientas se encuentran contenidas en los Sistemas de Información Geográfica.

La tercera etapa mediante la intersección de estas capas y las de planes habitacionales se logró identificar la distribución espacial de aquellos ejecutados por cada década analizada. La cartografía de base 
utilizada, en parte, fue producida a partir de la interpretación visual de las imágenes satelitales y tiene que ver con la mancha urbana en diferentes momentos; por otro lado, las capas de base, como por ejemplo el catastro urbano y la localización de los planes de viviendas, fueron proporcionados por el Instituto Provincial de Desarrollo Urbano y Vivienda de la Provincia del Chaco (IPDUV). Las etapas metodológicas lograron concretar en cierta medida un objetivo primordial del proyecto mayor de investigación en el que se inserta este trabajo que consiste en elaborar una base de datos georreferenciada como insumos concretos para el estudio de la ciudad y cartografía temática de aporte a la gestión del territorio.

Figura 2. Etapas metodológicas

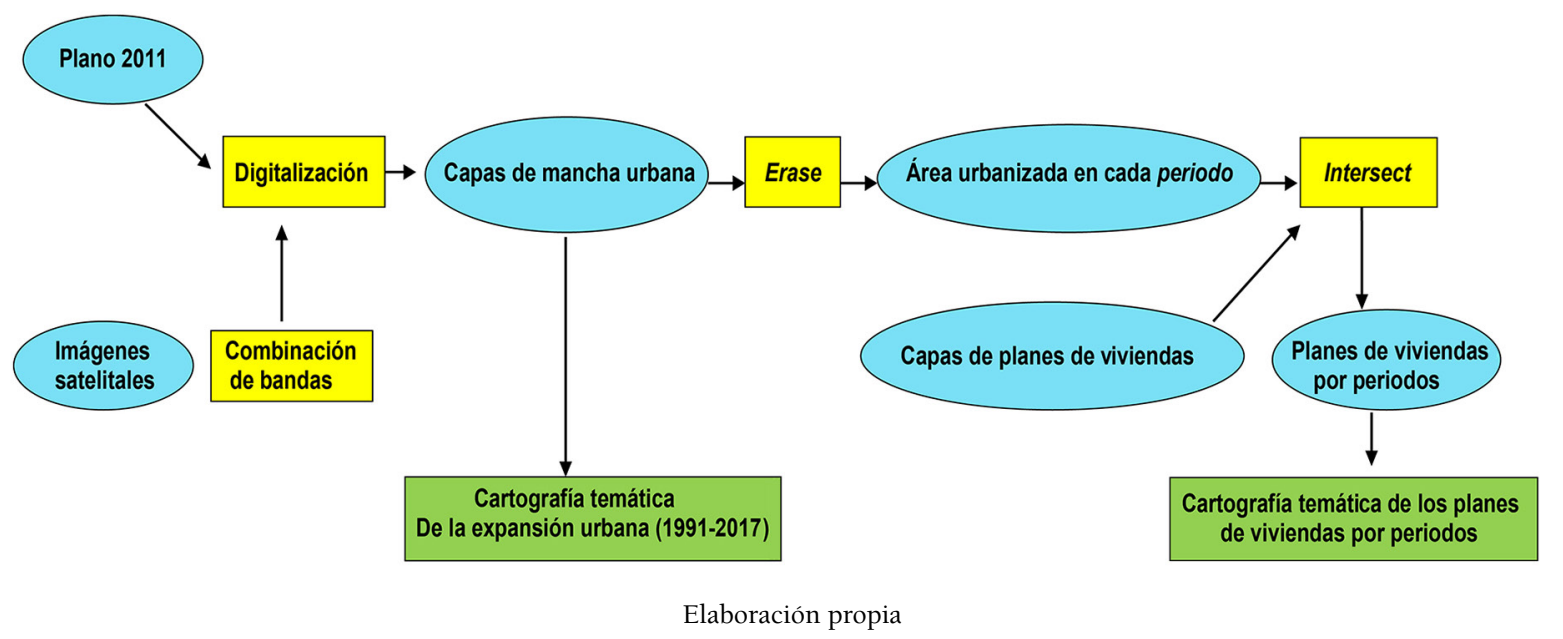

\section{Resultados}

\subsection{El Zapallar, fundación y asentamiento inicial}

La primera mensura realizada en la colonia "El Zapallar" (primer nombre que adquirió el asentamiento que hoy lleva por nombre General José de San Martín) data del período comprendido entre los años 1909 y 1911, cuando se llevó a cabo una primera subdivisión de las tierras destinada a su creación y lo que hoy es el área central del ejido urbano con 60 manzanas, de 100 metros por 100 metros separadas de calles de 20 metros de ancho (Guillón, 2011). Aquella primera delimitación del catastro estuvo trazada entre las Avenidas 25 de Mayo al norte, Mitre al este, San Martín al oeste y la calle Islas Malvinas al sur. Este límite sur luego se extendió a la Avenida Brown con la anexión de 40 manzanas, quedando así conformado un damero de 100 manzanas (Figura 3).

En la Figura 4 se observa el resultado del procesamiento realizado a las imágenes satelitales de los años 1984, 1991, 2001, 2010 y 2017, allí se detectan las diferentes coberturas y usos del suelo como ser urbano, vegetación nativa, actividades agropecuarias y, cuerpos y cursos de agua. A modo general, se observa una ampliación de la cobertura urbana en diferentes direcciones, principalmente hacia el este, sureste y norte, ocupando áreas que pertenecían a otras como actividades agropecuarias o vegetación nativa, así como una presión sobre los cuerpos y cursos de agua.

A partir de la digitalización de la mancha urbana en dichos cortes temporales y la superposición de las capas obtenidas, se puede notar en la Figura 5 la importante extensión que fue adquiriendo la ciudad en el período estudiado, a partir de este proceso, también fue posible cuantificar en hectáreas la cobertura urbana y vincular con los datos de cantidad de población urbana.

Si deseamos comparar las dimensiones que adquirió el área urbana en el período estudiado y su relación con la dinámica de crecimiento poblacional vamos a desglosar el análisis por etapas, apoyándonos en los datos de la Tabla 1.

- Etapa 1 (1911): La superficie de suelo urbano en este año era de 88 hectáreas dimensión que abarcaba el casco histórico y céntrico de la ciudad conformado por 60 manzanas, constituyó la primera mensura realizada con fines de urbanizar el núcleo central que se hallaba en la zona. La modalidad de ocupación, como se mencionó, respondió a la subdivisión de territorio en forma de un damero tradicional a partir del cual las familias que se encontraban en la colonia pudieron acceder a los terrenos loteados. 
Figura 3. Plano urbano de 1911

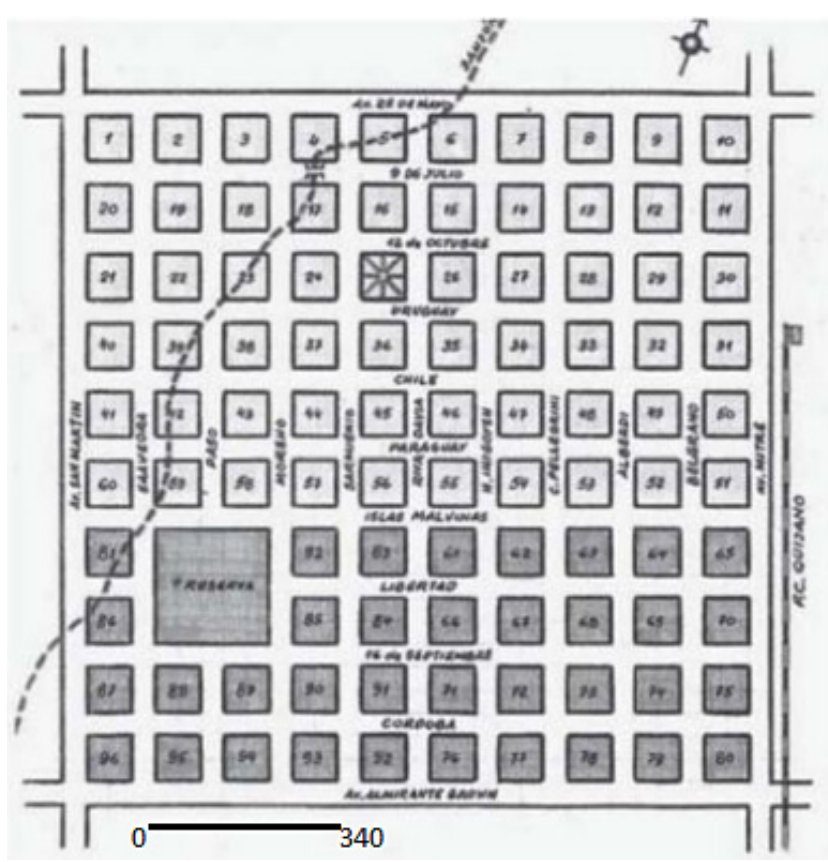

Fuente: Guillón (2011)

Figura 4. Combinación de bandas multiespectrales

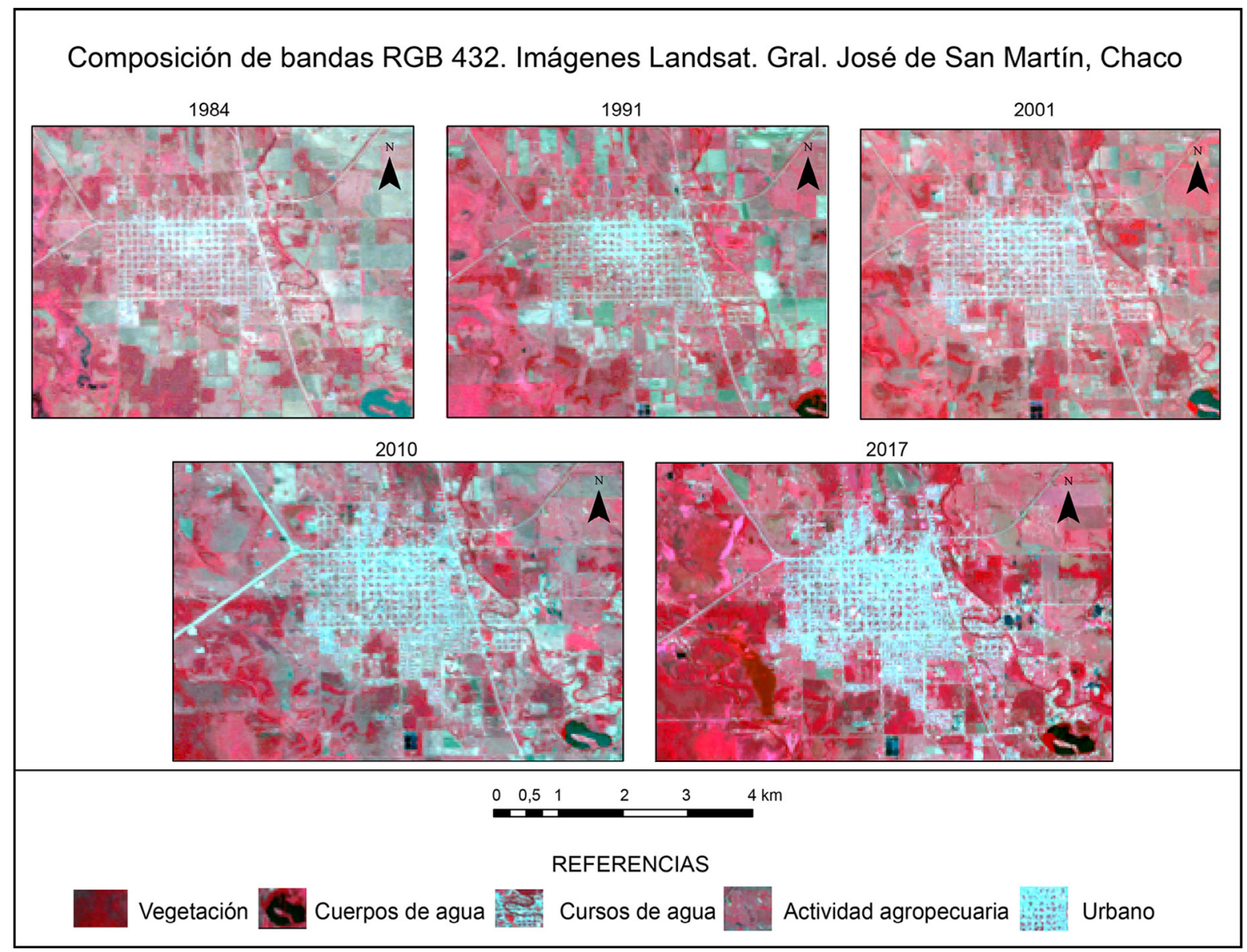

Fuente: Imágenes satelitales Landsat 5 y 8. Elaboración propia 
- Etapa 2 (1911-1984): Durante este periodo de análisis que abarca 73 años, debido a la falta de documentos cartográficos de años intermedios, la expansión se generó principalmente hacia el sur, este y oeste y tuvo como principal impulso la creación de barrios. A partir de la mancha urbana inicial, antes descrita, la primera ampliación, se realizó hacia el sur con la anexión de 40 manzanas conformando así un total de 100.La superficie urbanizada era de 351 hectáreas, es decir, se advierte un aumento de 263 hectáreas de suelo con actividades urbanas desde la primera mensura. Además, en este período es donde el número de población urbana del municipio comienza a superar al de población rural, cuando el Censo Nacional de Población y Viviendas registra el valor de 9.860 de población urbana por sobre 6.436 de población rural, a partir de aquí, el crecimiento de la primera es sostenido y se mantiene en las siguientes décadas. La densidad de población se ubica en torno a 46.3 habitantes/hectárea hacia el año 1984.

- Etapa 3 (1984-1991): En esta etapa por tratarse de un período más corto el aumento de suelo urbano solo se advierte en algunos sectores reducidos al norte, suroeste y sureste que suman un total de 32 hectáreas que se adicionan a la mancha existente. En el año 1991 la población urbana alcanza el total de 19.246 habitantes con un crecimiento relativo del $95,2 \%$ respecto al censo anterior y, considerando que en esta etapa el aumento de población fue importante en relación a superficie ocupada, se registra aquí el mayor valor de densidad de población alcanzando 50,2 habitantes/hectárea.

- Etapa 4 (1991-2001): Este periodo es en el que se produce la mayor anexión de suelo urbano, pues la expansión se produce en todas las direcciones y con mayor énfasis hacia el norte, sur y sureste, propiciado primordialmente por la promoción pública de conjuntos de viviendas que conformaron una periferia de nuevos barrios, se adiciona una superficie de 175 hectáreas a la mancha existente. Iniciaba el siglo XXI y el Censo Nacional de Población 2001 indicaba que la ciudad poseía 25.775 habitantes lo que representa un crecimiento relativo del 34\%. Ante la notable expansión horizontal, la densidad poblacional comienza a disminuir registrando en ese mismo año un valor aproximado de 46,2 habitantes/hectárea.

- Etapa 5 (2001-2010): En la primera década del siglo XXI se vuelve a producir un aumento de población, aunque no tan significativo, que alcanza 28.383 habitantes en el año 2010 (crecimiento relativo del $10,1 \%)$ y con ello, el de superficie urbanizada, aunque este último con un valor menor al período anterior, es así que 159 nuevas hectáreas se ubicaron mayormente en el norte y sur de la ciudad, a partir de ambos datos se advierte una densidad de población que desciende a 39,5 habitantes/hectárea. En esta etapa, la mancha urbana comienza a tener una mayor orientación norte-sur considerando las restricciones naturales del este y oeste, aunque se sigue ejerciendo presión sobre el sector este correspondiente a la planicie de inundación del río de Oro.

- Etapa 6 (2010-2017): El último período comprende desde el 2010 hasta 2017 donde la ocupación fue principalmente hacia el sureste siguiendo la ubicación de los terrenos más aptos topográficamente, aunque se detectan también nuevos sectores ocupados en el norte y suroeste, la superficie de aumento calculada para esta década fue de 105 hectáreas, conformando un total de 822 hectáreas de área urbana. En cuanto a la población, según la proyección estimada del INDEC en el 2017 el número de habitantes sería de 31.131, esto significa un crecimiento relativo bajo con un valor de $9,7 \%$, a la vez que la densidad de población también registra el valor mínimo que fue de 37,8 habitantes/hectárea, en relación a los demás años analizados.

Tabla 1. Crecimiento absoluto y relativo de población urbana y superficie urbanizada

\begin{tabular}{|c|c|c|c|c|c|c|c|}
\hline Año & $\begin{array}{c}\text { Población } \\
\text { urbana }\end{array}$ & $\begin{array}{c}\text { Crecimiento } \\
\text { absoluto de la } \\
\text { población }\end{array}$ & $\begin{array}{c}\text { Crecimiento } \\
\text { relativo de la } \\
\text { población }\end{array}$ & $\begin{array}{c}\text { Superficie } \\
\text { urbanizada } \\
\text { (hect áreas) }\end{array}$ & $\begin{array}{c}\text { Crecimiento } \\
\text { absoluto de } \\
\text { la superficie } \\
\text { urbanizada } \\
\text { (hectáreas) }\end{array}$ & $\begin{array}{c}\text { Crecimiento } \\
\text { relativo de } \\
\text { la superficie } \\
\text { urbanizada }\end{array}$ & $\begin{array}{c}\text { Densidad de } \\
\text { población }\end{array}$ \\
\hline $\mathbf{1 9 1 1}$ & - & - & - & 88 & - & - & - \\
\hline $\mathbf{1 9 8 0}$ & 9.860 & - & - & $351(1984)$ & 263 & $299 \%$ & 46,3 \\
\hline $\mathbf{1 9 9 1}$ & 19.243 & 9.383 & $95,2 \%$ & 383 & 32 & $9,1 \%$ & 50,2 \\
\hline $\mathbf{2 0 0 1}$ & 25.775 & 6.532 & $34 \%$ & 558 & 175 & $46 \%$ & 46,2 \\
\hline $\mathbf{2 0 1 0}$ & 28.383 & 2.608 & $10,1 \%$ & 717 & 159 & $28,5 \%$ & 39,5 \\
\hline $\mathbf{2 0 1 7}$ & $31.131^{3}$ & 2748 & $9,7 \%$ & 822 & 105 & $14,6 \%$ & 37,8 \\
\hline
\end{tabular}

Fuente: Capas SIG y Censos Nacionales de Población y Vivienda. Elaboración propia

3 Proyección de la población en base a datos del Censo 2010 del INDEC. 
Figura 5. Expansión urbana de Gral. José de San Martin, Chaco, República Argentina (1911- 2017)

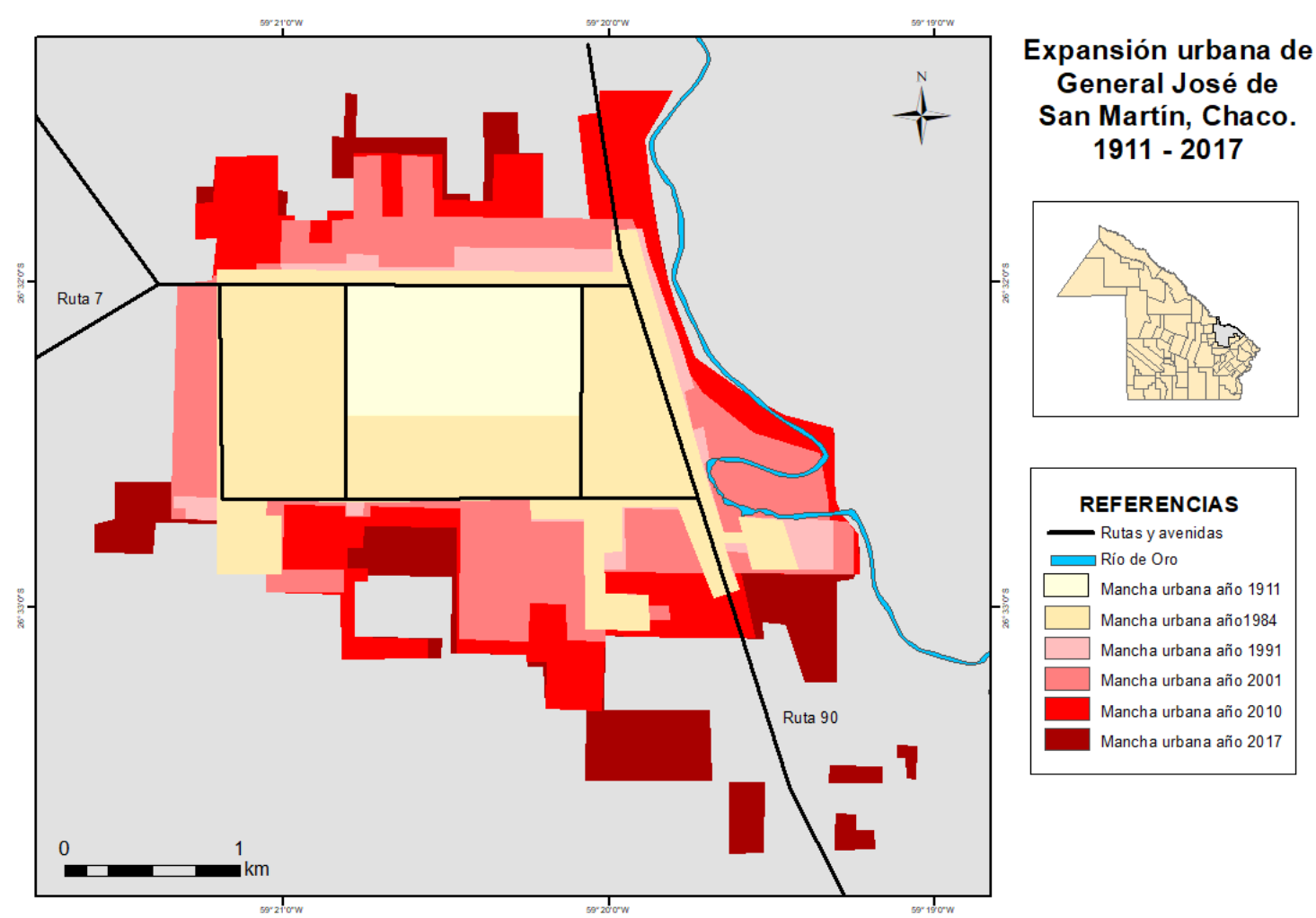

Fuente: Plano catastral (1911) e imágenes satelitales Landsat (1984 a 2017). Elaboración propia

\subsection{Los conjuntos habitacionales de promoción estatal}

Siguiendo con los objetivos de este trabajo, en esta segunda parte se pretende reconocer cual fue la incidencia de una de las modalidades de ocupación del suelo que contribuye a la expansión urbana y tiene que ver con la construcción de conjuntos habitaciones estatales o complejos de viviendas sociales.

Atendiendo al caso de estudio, como puede observarse en el mapa de localización de los conjuntos habitacionales (Figura 6), éstos conforman un cinturón periférico en el área urbana que se viene consolidando desde la década de 1980 con lo cual representa una de las causas de la expansión de la mancha urbana antes expuesta, su presencia se observa con mayor concentración en el sur de la ciudad, lo que significó un gran impulso a la ocupación de suelo en esta dirección. Además, se ubican otros polígonos en el norte y noreste, y llaman particularmente la atención aquellos localizados en las riberas del Río de Oro, sobre todo por tratarse de residencias entregadas por el Estado.

En la Tabla 2 y Figura 7, se encuentra diferenciada, por períodos, la relación entre el área urbanizada (AU) y la superficie ocupada por los polígonos que representan las viviendas sociales. Allí mismo se puede apreciar que el período de mayor incidencia fue hasta 1984 y durante la década del noventa. En el primero, a pesar de ser un valor relativo bajo $(6,8 \%)$ en relación al aumento de suelo urbano desde la fundación de la ciudad, el valor absoluto de extensión ocupada por los planes ejecutados se lo considera importante(18 hectáreas) ya que se puede afirmar que esta modalidad comenzó a instalarse desde fines de la década del '70; así, en poco tiempo, e inmediatamente, este tipo de urbanización comenzó a tener repercusión en la expansión de la ciudad, principalmente hacia el sureste y suroeste; en términos relativos, la mayor incorporación de superficie urbanizada fue mayormente impulsada por esta modalidad entre las década del 70 y ' 80 . En cuanto al segundo período de mayor promoción de los planes estatales, es decir los años '90, han aportado el mayor valor de superficie de viviendas sociales a la mancha urbana (24 hectáreas) lo que representó un 13,7\% de total de suelo urbanizado en dicha década. Por el contrario, se observa que las etapas de menor intervención fueron las de 1984-1991 y 2010-2017 época en que el incremento de suelo con fines residenciales a partir de la modalidad de conjunto habitacionales solo fue de 5 hectáreas en cada periodo. 
Figura 6. Localización de los planes de viviendas en Gral. José de San Martin año 2017

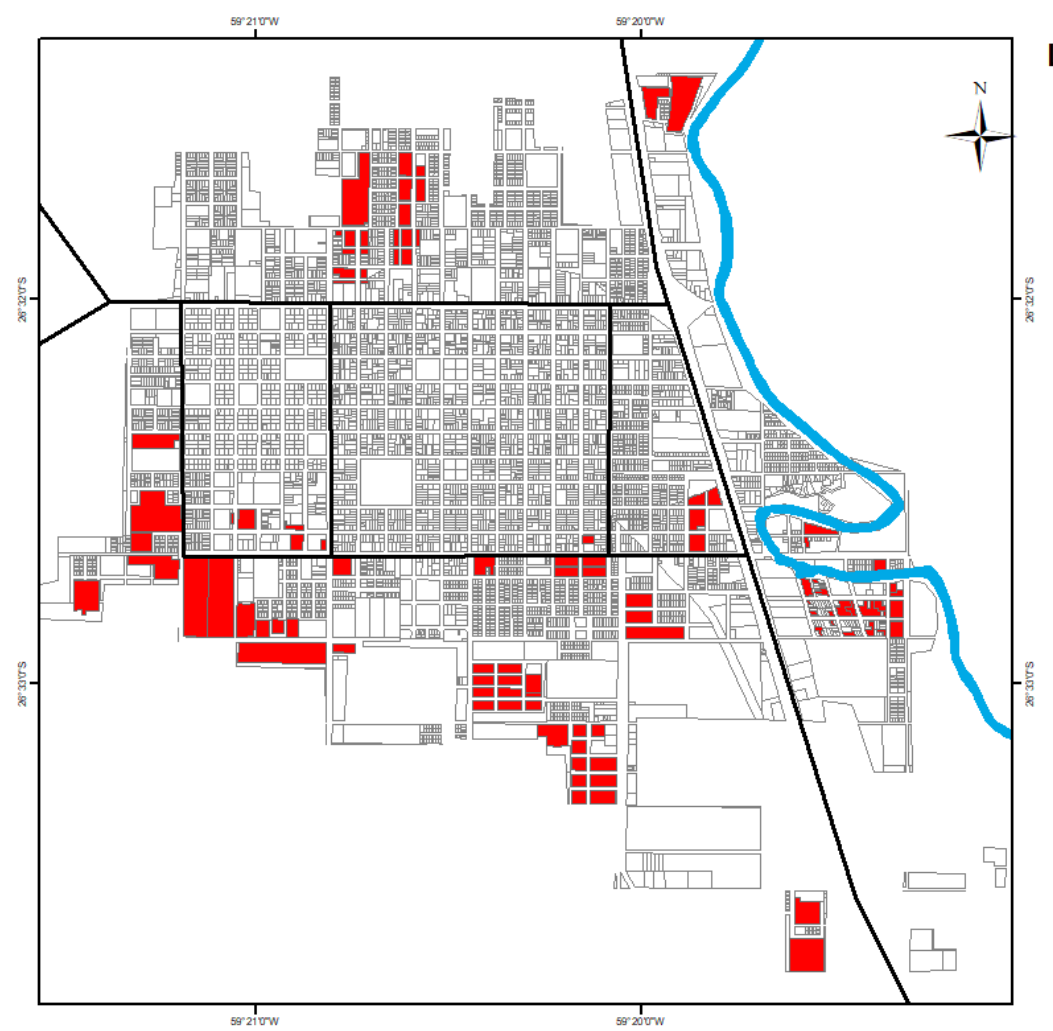

\section{Localización de planes de viviendas}

Gral. José de San Martín, Chaco.

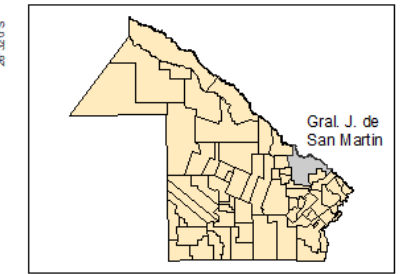

\section{Referencia}

Planes de vivienda

Fuente: Instituto Provincial de Desarrollo Urbano y Vivienda (IPDUV). Elaboración propia

Figura 7. Localización de los planes de viviendas según periodo de ejecución

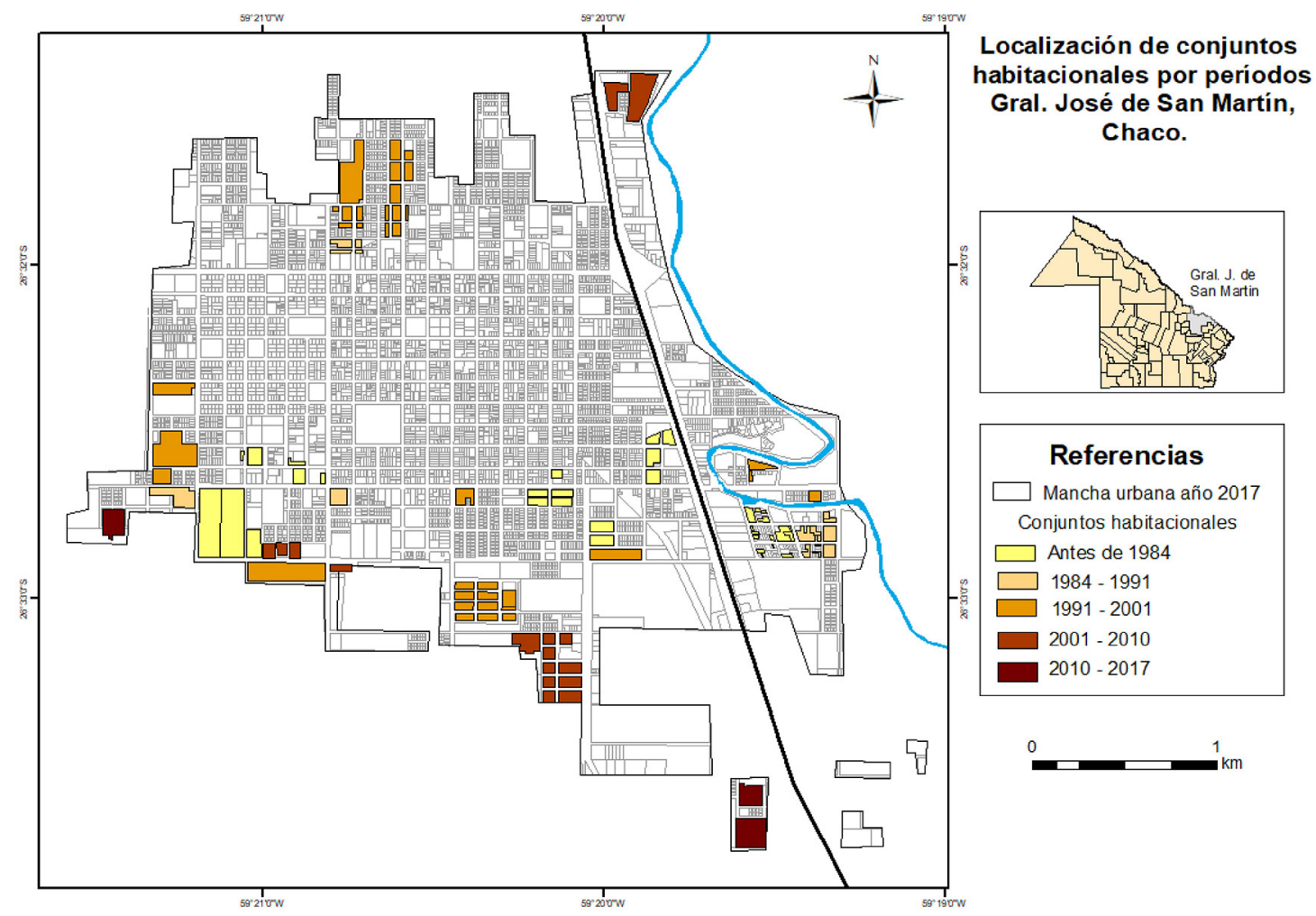

Fuente: Instituto Provincial de Desarrollo Urbano y Vivienda (IPDUV). Elaboración propia 
Tabla 2. Superficie urbanizada y superficie ocupada por polígonos de viviendas sociales

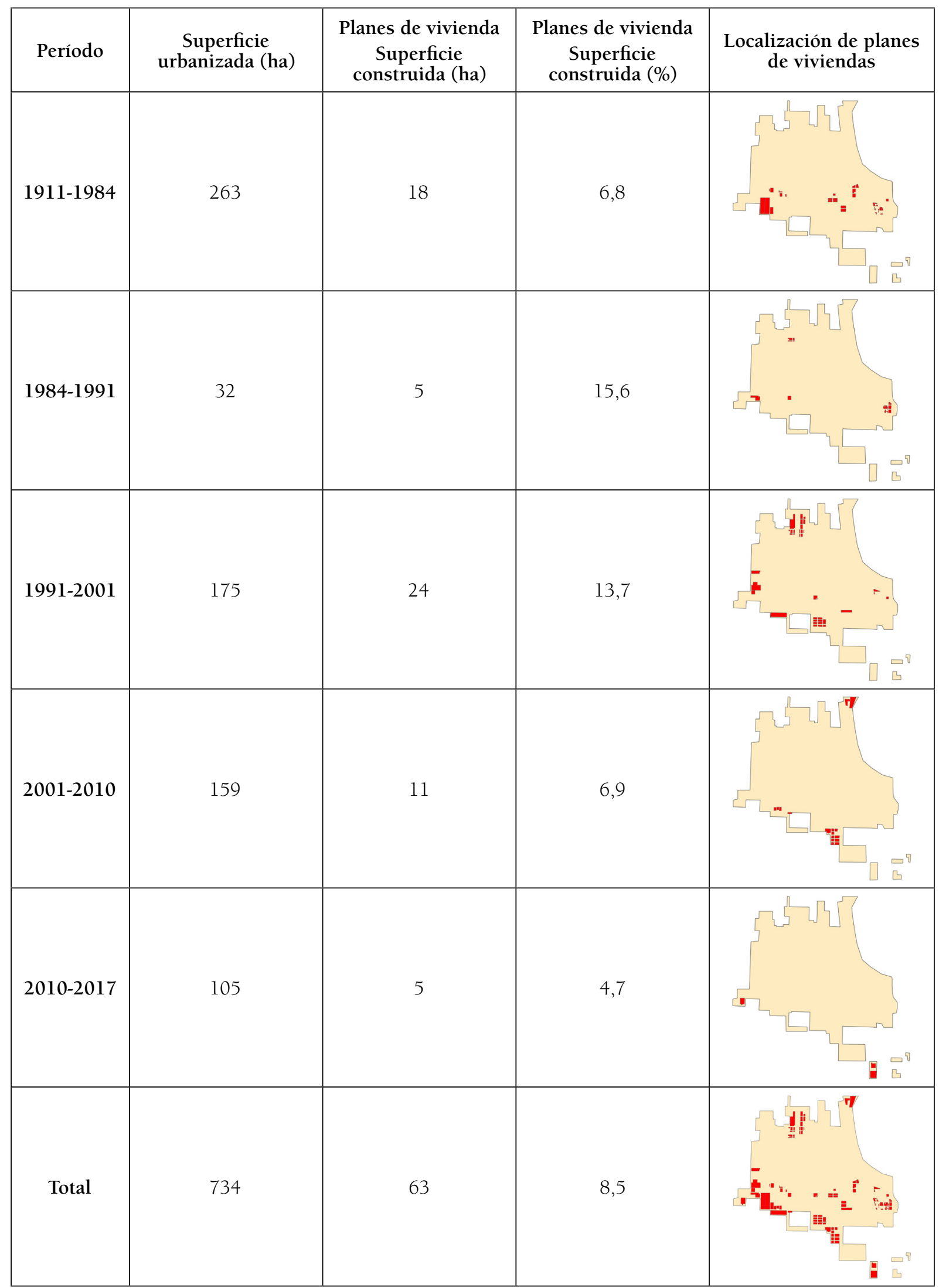

Fuente: Datos obtenidos de las capas SIG. Elaboración propia 
Es posible visualizar en los mapas contenidos en el Tabla 2, tanto de cada uno de los periodos como el que contiene al total de polígonos, que la ejecución de complejos de viviendas sociales ha impulsado la expansión de la mancha urbana hacia todas las direcciones y se han configurado, durante casi cinco décadas, nuevas periferias que progresivamente se consolidan, este proceso ha ido acentuando el crecimiento horizontal de la ciudad.

\section{Discusión de resultados}

Los resultados obtenidos han permitido responder las preguntas iniciales que guiaron este trabajo y confirmar aquello que la idea central o hipótesis plantea, es decir, que la ciudad objeto de estudio experimentó una incesante expansión de su mancha urbana en el periodo analizado y los conjuntos habitacionales proporcionado por el Estado propician son uno de los elementos que propician dicha expansión, que a su vez generan espacios residenciales discontinuos y cada vez más alejados entre ellos y del centro de la ciudad, por ende, el abastecimiento de servicios comienza a verse dificultado.

Debemos tener en cuenta que para abordar la configuración de un espacio geográfico actual debemos realizar un análisis espacio-temporal, pues los estudios geográficos son básicamente abordajes del presente (recordemos que la Geografía generalmente se presentan como una ciencia del presente), sin embargo, en ningún momento se deja de reconocer que la dimensión temporal es de gran importancia en un análisis geográfico completo siendo que ir hacia el pasado nos muestra el origen de las manifestaciones empíricas del presente. "El concepto de evolución espacial considera la incorporación de la dimensión temporal a través de la permanente transición de un estado a otro" (Humacata y Buzai, 2018, p. 1001).

En ese sentido, el análisis temporo-espacial realizado pone de manifiesto en primer lugar que el crecimiento poblacional experimentado por la ciudad objeto de estudio se refleja claramente en la expansión de la mancha urbana en diferentes direcciones, principalmente hacia el este, sureste y norte. Si bien desde su fundación y hasta mediados de la década de 1980 el aumento de suelo urbano es evidente y se traduce en 263 hectáreas (299\%), el mayor crecimiento expansivo tuvo su auge a partir de 1984 que hasta el año 2017, incrementó 471 hectáreas en 33 años, en valores relativos significa 134\%. En este último período de cuatro décadas, si consideramos los datos de población, se puede mencionar que aproximadamente, por cada año desde 1980 hubo un aumento de 644 personas y desde 1984 se incrementó 14,3 hectáreas de suelo urbano por año. Asimismo, se advierte el descenso en los valores absolutos y relativo de crecimiento poblacional y densidad que alcanzan en la últimas dos décadas valores mínimos y similares.

En cuanto a las causas que han conducido estos patrones de expansión, una de ellas puede relacionarse con las diferentes modalidades de ocupación o producción del suelo urbano que diferentes momentos históricos y la situación socioeconómica de los grupos sociales ha determinado, principalmente por loteo y urbanización tradicional, conjuntos habitaciones propiciados por el Estado y asentamientos informales u ocupación ilegal que, posteriormente pudieron o no haber regularizado su situación dominial, la fisonomía de cada categoría se pueden visualizarse en imágenes satelitales tal como se observa en la Figura 8. Estos diferentes tejidos urbanos serán objeto de estudio en futuros trabajos en una línea de análisis similar, así se ha decidido en este caso aproximarnos al segundo tipo mencionado, las viviendas sociales.

Figura 8. Modalidades de ocupación del suelo urbano en el área de estudio

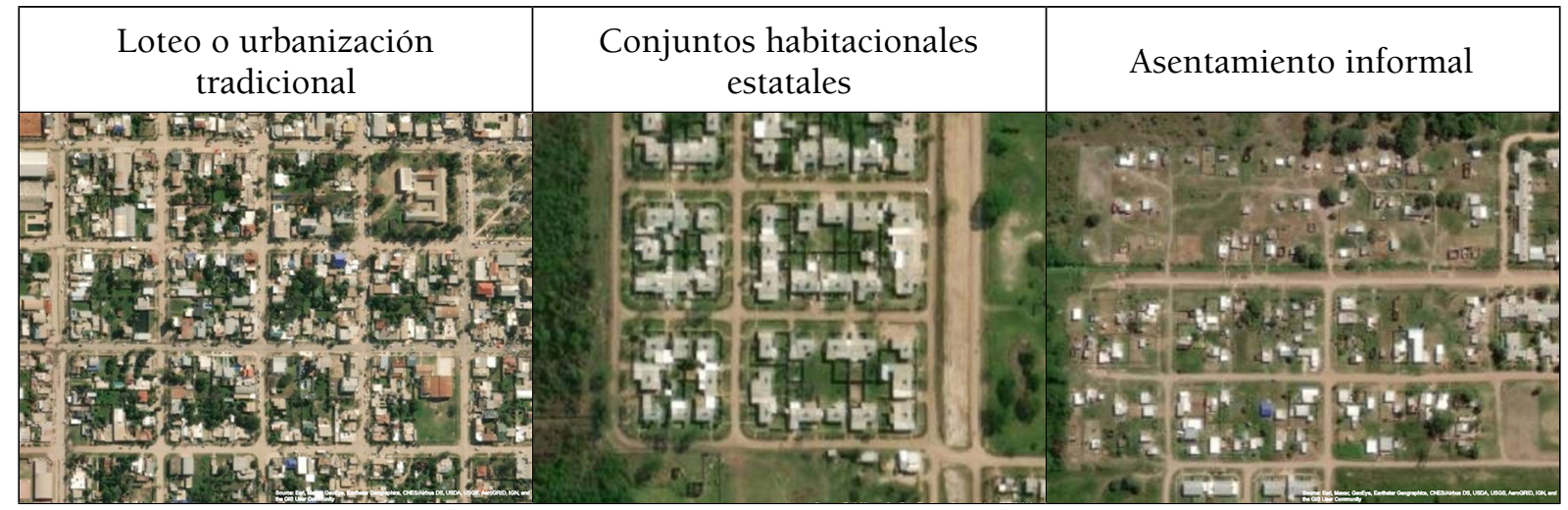

Fuente: Imagen satelital World Imagery 
Respecto de la ejecución de los conjuntos habitacionales, en la Provincia del Chaco, el organismo encargado es el Instituto Provincial de Desarrollo Urbano y Vivienda (IPDUV). Esta institución, es el agente que atiende las demandas habitacionales y fue históricamente uno de los principales actores de la expansión de los núcleos urbanos de la provincia. Al respecto Romagnolli (2015) señala:

La lógica de localización de los numerosos conjuntos habitacionales nuevos que construyó, siempre obedeció a los intereses inmobiliarios de valorizar tierras periurbanas de bajo costo. Esto dio como resultado a lo largo del tiempo, una expansión discontinua y de muy baja densidad, que afectó la adecuada provisión de infraestructuras, servicios y equipamientos sociales, y, por ende, la calidad de vida los habitantes de las periferias urbanas (p.153).

En palabras de Barreto (2002):

Estas urbanizaciones fueron modificándose en su concepción desde sus inicios, al principio, en la década del ' 60 , se construyeron en forma de viviendas individuales respetando el trazado tradicional de la ciudad, desde fines de la década del '70, con la creación del Fondo Nacional de la Vivienda (FONAVI), se intensificó la producción en forma de edificios colectivos de densidad poblacional media, ubicados sobre trazados urbanos diferentes al damero de la ciudad y, en los últimos tiempos, nuevamente han vuelto a la forma urbana tradicional de la región: viviendas individuales de baja densidad poblacional sobre manzanas estándares, aunque sobre una base de mayor diversidad de programas orientados a diferentes tipos de población objeto (p.12).

Actualmente en la mayor parte del cordón periférico se localizan barrios de viviendas sociales, un tipo de tejido urbano muy particular, los cuales adquieren ubicaciones cada vez más distantes entre ellos y del centro de la ciudad, resultando poco beneficioso dado el costo que conlleva la ampliación de las redes de infraestructuras y servicios, a la vez que se evidencia una tendencia a la dispersión y sus consecuentes impactos en el ambiente, principalmente una presión sobre la vegetación nativa y los cuerpos y cursos de agua del área circundante del ejido urbano.

Además, este proceso de expansión propiciada por esta modalidad en localizaciones cada vez más alejadas comienza a mostrar indicios de dificultades a sus propietarios en cuanto la accesibilidad a determinados sitios vinculados con el trabajo, y los servicios: educación, salud, recreación, ya que si bien la provisión de bienes y los equipamientos mínimos está disponible, una localización alejada con la deficiente cobertura de servicios de transporte le niega a sus habitantes la posibilidad de interacción y contacto con personas y lugares diferentes, así como de otros sectores de la ciudad.

El alejamiento del barrio con respecto al centro de la ciudad, y cierto aislamiento por baldíos interpuestos entre el borde edificado de la misma y las nuevas construcciones, afectan la accesibilidad a algunos servicios, dificultando la vinculación efectiva con el resto de la ciudad (Sardi, 2015, p. 45).

Este patrón de ocupación trae aparejado otros procesos tales como la fragmentación física del espacio urbano ya que se observa una discontinuidad de la trama urbana por la presencia de áreas intersticiales. Como bien expresan Dillón y Cossio, (s/f_a) posibilitar a través de políticas de ordenamiento urbano, la integración de los conjuntos habitacionales al gran conjunto de la ciudad, es indispensable para evitar perturbaciones de orden funcional y desorganización de la trama urbana existente.

\section{Conclusiones}

La finalidad de este trabajo ha sido el de indagar cómo se materializó la expansión urbana de la ciudad de General José de San Martín (Chaco) y cómo ha sido la incidencia que han tenido los planes de viviendas estatales en la configuración de la mancha urbana. Al respecto se ha logrado realizar un análisis de la evolución espacial de la misma y se pudo generar evidencias de los siguientes aspectos.

En su evolución histórica la mancha urbana de General San Martín aumentó considerablemente sus dimensiones después de 1911, momento en el que quedo definida la trama y mensura original mostrándose como una ciudad compacta que mantuvo su morfología hasta el inicio del proceso de urbanización reciente a partir de la década del ochenta, y luego, desde la década del noventa comenzó a registrar los mayores incrementos de suelo urbano exhibiendo patrones dispersos y discontinuos hacia la periferia. Dicho crecimiento se materializó hacia todas las direcciones pero con mayor énfasis hacia el sur, demostrando indicios del desarrollo de un modelo de ciudad dispersa. 
La ejecución de planes de viviendas estatales fue uno de los promotores de la expansión horizontal de la ciudad, principalmente hacia el sur. El período de mayor intervención estatal mediante la modalidad de urbanización de viviendas sociales se registra a finales de la década de 1970 e inicio de la década siguiente y con mayor fuerza en la década de 1990.

Mediante la representación cartográfica se pudo detectar que las viviendas sociales son uno de los elementos estructurantes del espacio urbano y organizan, a su vez, las nuevas periferias. Es evidente el rol protagónico del Estado en la conformación de nuevas áreas de expansión en la ciudad, por ello, es necesario la implementación de políticas territoriales que orienten el proceso de expansión urbana hacia el uso racional de suelo y evitar futuras problemáticas ambientales como ocupación de ambientes inundables y anegadizos, deterioro del paisaje y creciente dispersión con insuficiencia en la extensión de los servicios públicos.

Las Tecnologías de la Información Geográfica y en particular los Sistemas de Información Geográfica suponen un recurso fundamental para el acercamiento a la realidad territorial de espacios urbanos, tanto para su diagnóstico o el conocimiento de su configuración actual como para su gestión, pues como señala Díaz (2009):

No se puede administrar lo que no se conoce, lo que no se puede cuantificar, lo que no se puede ubicar. Una vez aceptado esto, resulta indiscutible que en todo proceso de planificación y ordenamiento, la información (ordenada, sistematizada, documentada, actualizada) juega un rol fundamental como instrumento de argumentación para la toma de decisiones (p. 9).

\section{Financiación}

Este trabajo se enmarca en el proyecto "Crecimiento urbano y salud ambiental de en ciudades intermedias de la Provincia del Chaco (1990-2015)". SGCyT - UNNE, PI: 16HOO5 (2017-2020), directora Dra. Liliana Ramírez. Además fue financiado por el Consejo Nacional de Investigaciones Científicas y Técnicas (CONICET).

\section{Referencias}

Azócar G., Sanhueza, R., \&Henríquez, C. (2003). Cambio en los patrones de crecimiento en una ciudad intermedia: el caso de Chillán en Chile Central. Revista eure, XXIX(87), 79-92. Recuperado de https:// scielo.conicyt.cl/pdf/eure/v29n87/art06.pdf

Barreto, M. (2002). El crecimiento de las ciudades Intermedias del NE argentino en el contexto de las transformaciones regionales. Cuaderno Urbano, 3, FAU-UNNE / FAU-UNLP. http://dx.doi. org/10.30972/crn.331611

Bazant, J. (2008). Procesos de expansión y consolidación urbana de bajos ingresos en las periferias. Bitácora, 13(2), 117-132. Recuperado de http://www.redalyc.org/articulo.oa?id=74811925009

Buzai, G., \& Baxendale, C. (2013). Aportes del análisis geográfico con Sistemas de Información Geográfica como herramienta teórica, metodológica y tecnológica para la práctica del ordenamiento territorial. Persona y Sociedad, XXVII(2), 113-14. Recuperado de https://personaysociedad.uahurtado.cl/index. $\mathrm{php} / \mathrm{ps} / \mathrm{article} / \mathrm{view} / 43$

Del Río, J. P. (2012). El lugar de la vivienda social en la ciudad: Un análisis de la política habitacional desde el mercado de localizaciones intra-urbanas y las trayectorias residenciales de los habitantes (Tesis de Maestría). Universidad Nacional de La Plata. Facultad de Humanidades y Ciencias de la Educación. Recuperado de http://www.memoria.fahce.unlp.edu.ar/tesis/te.464/te.464.pdf

Díaz, B. (2009). El proyecto Sistema de Información Territorial de Santa Cruz (SIT SantaCruz). En B.G. Diaz. y P. Calviño (Compiladores), Jornadas Regionales de Información Geográfica y Ordenamiento Territorial (pp. 9-19). Ministerio Secretaría General de la Gobernación, Proyecto SIT Santa Cruz.

Dillón, B., \& Cossio, B. (s/__a). El problema socioespacial de los barrios planificados de la ciudad de Santa Rosa, La Pampa, Argentina. Recuperado de http://observatoriogeograficoamericalatina.org.mx/egal6/ Geografiasocioeconomica/Geografiaespacial/413.pdf

Dillón, B., \& Cossio, B. (s/f_b). Los programas de viviendas sociales en la construcción del espacio urbano en una ciudad intermedia. Santa Rosa. La Pampa. Argentina. Recuperado de http:// observatoriogeograficoamericalatina.org.mx/egal8/Geografiasocioeconomica/Geografiaurbana/35.pdf 
Dillón, B., Cossio, B., \& Pombo, D. (2010). Valor del suelo urbano en una ciudad intermedia: la volatilidad del capital y sus resultados efímeros. Scripta Nova. Revista Electrónica de Geografía y Ciencias Sociales, XIV(331/34). Recuperado de http://www.ub.es/geocrit/sn/sn-331/sn-331-34.htm

Gómez López, C. (2002). El fenómeno del crecimiento urbano. Una experiencia de análisis con un sistema de información geográfica. Revista INVI, 17(45), 171-182. Recuperado de http://revistainvi. uchile.cl/index.php/INVI/article/view/127

Guillón, R. (2011). El Zapallar, tenemos historia. Resistencia, Chaco, Argentina: Librería de la Paz.

Humacata, L., \& Buzai, G. (2018). Análisis espacial de los cambios de usos del suelo con Sistemas de Información Geográfica. En C. Mikkelsen \& N. Picone (Comp.), Geografias del presente para construir el mañana: miradas geográficas que contribuyen a leer el presente. $1^{a}$ Ed. Tandil: Universidad Nacional del Centro de la Provincia de Buenos Aires. Recuperado de https://ri.unlu.edu.ar/xmlui/bitstream/ handle/rediunlu/791/buzai.pdf? sequence $=1$ \&isAllowed $=y$

Lancioni, A., Delachaux, A., \& Ríos, L. (2012). Expansión urbana en municipios bonaerenses: Alcances y vínculos con las políticas de tierra y vivienda. Actas $7^{\circ}$ Congreso de Medio Ambiente AUGUM. UNLP. La Plata, Argentina. Recuperado de http://sedici.unlp.edu.ar/handle/10915/26680

Manzano, F, \& Velázquez, G. (2015). La evolución de las ciudades intermedias en la Argentina. Revista GeoUERJ, 27, 258-282. https://doi.org/10.12957/geouerj.2015.18859

Ramírez, L. (2018). La salud ambiental y los procesos de urbanización de ciudades intermedias en el Chaco. Aportes para la intervención territorial. En T. Artieda, M.J. Simoni y G. Vega (Comp.), III Jornadas de Intercambio de la Producción Científica en Humanidades y Ciencias Sociales (pp. 23-25). Facultad de Humanidades, UNNE. Recuperado de https://hum.unne.edu.ar/publicaciones/invest posgrado/terceras_jornadas.pdf

Ramírez, L., \& Pértile V. (2013). Cambio de uso de suelo y tendencias de la expansión urbana entre 1990 y 2030 en Juan José Castelli y villa Ángela, Chaco, Argentina. Geografía y Sistemas de Información Geográfica (GEOSIG), 5(5), 194-216. Recuperado de https://docs.wixstatic.com/ ugd/79758e_86dffc357db74c17b170acd58bcld69d.pdf

Ramírez, L., \& Pértile V. (2017). Crecimiento poblacional, expansión urbana y cambio de usos de suelo en ciudades intermedias de la provincia del Chaco, Argentina. El caso de Juan José Castelli. Estudios socioterritoriales, 21, 111-131. Recuperado de https://ojs2.fch.unicen.edu.ar/ojs-3.1.0/index.php/ estudios-socioterritoriales/article/view/289

Romagnolli, V. (2015). ¿Qué vivienda necesitan los pobres? Un estudio sobre la configuración de las necesidades en las políticas habitacionales vigentes a partir del caso del Área Metropolitana Gran Resistencia- AMGR (Chaco, Argentina) (Tesis doctoral). Facultad Latinoamericana de Ciencias Sociales, sede académica Argentina. Recuperado de https://repositorio.flacsoandes.edu.ec/ bitstream/10469/9988/2/TFLACSO-2016VR.pdf

Sardi, M. (2015). Las viviendas sociales, las políticas públicas y el derecho a una ciudad intermedia. Santa Rosa, La Pampa. Revista Huellas, 19, 34-50. Recuperado de https://cerac.unlpam.edu.ar/index.php/ huellas/article/view/1011/1031

Tella, G. (s/f). Cómo crece la ciudad: lógicas de un acuerdo social. Recuperado de https://www.guillermotella. com/articulos/como-crece-la-ciudad-logicas-de-un acuerdo-social/ 